\title{
Airway Clearance Therapy: Finding the Evidence
}

\author{
Teresa A Volsko MHHS RRT FAARC
}

\author{
Introduction \\ Airway Clearance Therapy: What Is It and Why Is It Needed? \\ Impairment of Secretion Clearance and Pulmonary Disease \\ Neurorespiratory Dysfunction and Secretion Clearance Problems \\ Indications for Airway Clearance \\ Where to Look for Current Evidence \\ Studies \\ Synthesis \\ Systematic Reviews \\ Evidenced-Based Clinical Practice Guidelines \\ Putting Evidence Into Practice \\ Summary
}

\begin{abstract}
Disease processes can impair ciliary function, alter secretion production and mucus rheology, and interfere with the cough reflex. Airway clearance therapy has been a cornerstone of therapy aimed at minimizing the devastating effects of airway obstruction, infection, and inflammation due to mucus stasis on the conducting airways and lung parenchyma. Although challenges to performing clinical studies evaluating the effectiveness of airway clearance therapeutic modalities exist, resources are available in the literature. In addition to device evaluations and original clinical research, the expert opinion, systematic reviews, and evidence-based practice guidelines can be found. These tools can be used to develop protocols and pathways to guide our practice. Monitoring and reporting patient, process, and financial outcomes are essential steps germane to the implementation of evidence-based care. Key words: airway clearance devices; cough; mucociliary transport; postural drainage; active cycle of breathing; positive expiratory pressure; oscillatory positive expiratory pressure; HFCWO; secretion clearance. [Respir Care 2013;58(10):1669-1678. (C) 2013 Daedalus Enterprises]
\end{abstract}

\section{Introduction}

The mucociliary escalator and cough reflex maintain optimal function of the respiratory system by removing

\footnotetext{
Ms Volsko is affiliated with the Department of Respiratory Care, Akron Children's Hospital, Akron, Ohio.

Ms Volsko presented a version of this paper at the 28th New Horizons in Respiratory Care Symposium, "The Scientific Basis for Respiratory Care," at the AARC Congress 2012, held November 10-13, 2012, in New Orleans, Louisiana.
}

The author has disclosed no conflicts of interest. secretions and preventing airways obstruction. In health, $10-100 \mathrm{~mL}^{1}$ of airway secretions are continuously produced and cleared by the centripetal movement of the mucociliary escalator, and with the aid of transient increases in expiratory air flow. ${ }^{2}$ There are a variety of factors that can interfere with the body's natural defense mech-

\footnotetext{
Correspondence: Teresa A Volsko MHHS RRT FAARC, Department of Respiratory Care, Akron Children's Hospital, One Perkins Square, Akron OH 44308. E-mail: tvolsko@chmca.org.
}

DOI: $10.4187 /$ respcare.02590 
Table 1. Types of Airway Clearance Modalities Available to Facilitate Secretion Removal

\begin{tabular}{|c|c|}
\hline Technique/Device & Description \\
\hline \multicolumn{2}{|l|}{ Breathing techniques } \\
\hline Active cycle of breathing & $\begin{array}{l}\text { A breathing technique that uses alternating cycles of breathing control or relaxed breathing, } \\
\text { thoracic expansion exercises to mobilize secretions, and the forced expiration technique } \\
\text { to facilitate secretion removal. }{ }^{13}\end{array}$ \\
\hline Autogenic drainage & $\begin{array}{l}\text { A technique that uses breathing at the low volumes to loosen secretions, a normal tidal } \\
\text { volume to collect secretions, and large lung volumes to maximize expiratory flow and } \\
\text { move secretions from the central airways where they can be cleared by a cough. }{ }^{13}\end{array}$ \\
\hline \multicolumn{2}{|l|}{ Manual techniques } \\
\hline Postural drainage & $\begin{array}{l}\text { The use of patient positioning to assist gravity in facilitating the movement of secretions } \\
\text { from peripheral airways to the larger bronchi where they can be cleared. }{ }^{14}\end{array}$ \\
\hline Clapping, percussion, and vibration & $\begin{array}{l}\text { Clapping or percussion is the manual external striking of the chest wall with a cupped } \\
\text { hand, or mechanical device in a rhythmic fashion to loosen secretions from the bronchial } \\
\text { walls. Vibrations are applied to the external chest wall by placing both hands (one over } \\
\text { the other) over the area of the patient's chest wall to be vibrated, then tensing and } \\
\text { contracting the shoulder and arm muscles while the patient exhales to mobilize } \\
\text { secretions cephalad. } .^{15}\end{array}$ \\
\hline \multicolumn{2}{|l|}{ Mechanical devices } \\
\hline Positive expiratory pressure (PEP) & $\begin{array}{l}\text { The PEP device consists of a user interface (face mask or mouthpiece) and a one-way } \\
\text { valve attached to an expiratory resistor. A manometer may be used to monitor pressures } \\
\text { during the maneuver. Tidal breathing, with a slightly active expiration through the } \\
\text { expiratory resistor will produce expiratory pressures of } 10-20 \mathrm{~cm} \mathrm{H}_{2} \mathrm{O} \text { at mid-expiration } \\
\text { to stent airways open, or increase intrathoracic pressure distal to retained secretions by } \\
\text { increasing functional residual capacity or collateral ventilation. }{ }^{16}\end{array}$ \\
\hline Oscillatory positive expiratory pressure (OPEP) & $\begin{array}{l}\text { OPEP therapy devices use a mechanical means to interrupt flow, and an expiratory resistor } \\
\text { to create air flow oscillations during active exhalation of a tidal volume breath through } \\
\text { the device. Air flow oscillations reportedly decrease the viscoelastic properties of mucus, } \\
\text { making it easier to mobilize. }{ }^{16}\end{array}$ \\
\hline High frequency chest wall compression & $\begin{array}{l}\text { An inflatable vest is used to apply high-frequency, small-volume expiratory pulses to the } \\
\text { external chest wall. Negative transrespiratory pressure is generated by the short, rapid } \\
\text { expiratory flow pulses at } 2-25 \mathrm{~Hz} \text {, to loosen, collect, and mobilize airway secretions. }{ }^{17}\end{array}$ \\
\hline Intrapulmonary percussive ventilation & $\begin{array}{l}\text { Intrapulmonary percussive ventilation creates a positive transrespiratory pressure by } \\
\text { injecting short, rapid inspiratory flow pulses into the airway opening, and relies on chest } \\
\text { wall elastic recoil for passive exhalation. }\end{array}$ \\
\hline Mechanical cough assist & $\begin{array}{l}\text { Positive pressure is provided during inspiration to provide a slightly larger than tidal } \\
\text { breath, followed by negative pressure to expel secretions from the airways. Typically } 5 \\
\text { cycles of positive (inspiration) and negative (expiration) pressure breaths are followed by } \\
\text { a period of normal breathing or ventilator use for } 20-30 \text { seconds, to avoid } \\
\text { hyperventilation. The sequence is repeated until no further secretions are expulsed. }\end{array}$ \\
\hline
\end{tabular}

anism, making it difficult to mobilize and evacuate secretions from the airways. The aging process, tobacco use, and environmental exposures reduce the efficacy of ciliary structure and function. ${ }^{3-6}$ Disease processes such as progressive neurodegenerative conditions inhibit the normal cough reflex.7,8 Pulmonary disorders such as cystic fibrosis (CF), COPD, and bronchiectasis alter the production and composition of mucus, and mucociliary clearance disorders, such as primary ciliary dyskinesia, reduce the efficacy of ciliary structure and function. ${ }^{9-11}$

Airway obstruction and structural damage to the airways and lung parenchyma result from recurring secretion retention, infection, and inflammatory changes. As a result, airway clearance techniques (ACTs) and devices are used to aid in mucus mobilization and expectoration. The objectives of this paper are to describe and review the need for ACTs, discuss methodological challenges and limitations to study design, and to describe methods for applying evidence to clinical practice.

\section{Airway Clearance Therapy: What Is It and Why Is It Needed?}

ACT utilizes physical or mechanical means to manipulate air flow, aid in the mobilization of tracheal bronchial phlegm cephalad, and facilitate evacuation by coughing. ${ }^{12}$ Breathing maneuvers, ${ }^{13}$ gravity assisted drainage, ${ }^{14}$ manual techniques, ${ }^{15}$ and/or mechanical devices ${ }^{16-18}$ can be used to alter air flow and/or produce a cough or cough-like effect (Table 1). Patient age, disease severity, ease of use, 

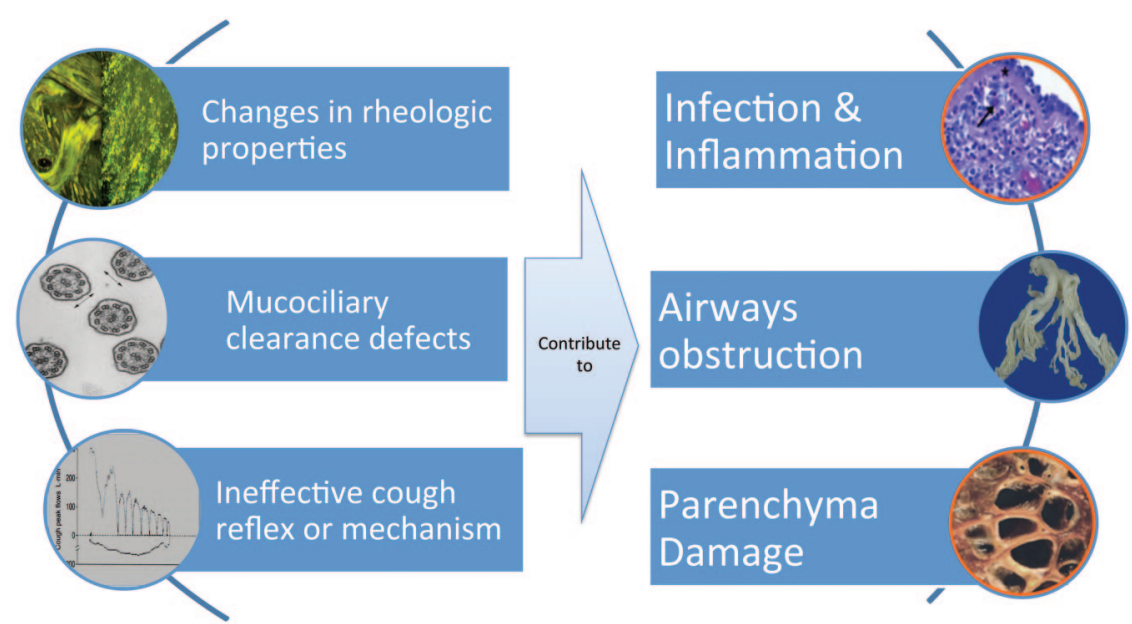

Fig. 1. Physiological factors that reduce the efficacy of mucociliary escalator function.

comfort, and cost affect device selection, adherence to prescribed plan, and the efficacy with which secretions are removed.

There are a number of disease processes that impair ciliary function, alter secretion production and mucus rheology, and interfere with the cough reflex. Secretions that accumulate or are stagnant obstruct conducting airways, are conduits for bacterial colonization and infection, evoke inflammatory response, and contribute to airway and parenchymal damage (Fig. 1).

\section{Impairment of Secretion Clearance and Pulmonary Disease}

Rare genetic disorders such as primary ciliary dyskinesia and Kartagener syndrome impair cilia structure and function. ${ }^{19,20}$ Although manifestations of these disorders also include chronic sinusitis, sinus hypoplasia, and secretory otitis media, repeated lower-respiratory-tract infections contribute to the development of bronchiectasis. ${ }^{21}$ Ciliary function is also altered with chronic pulmonary disease such as asthma, COPD, and CF. The literature reports impaired ciliary function, and changes in the flow or surface properties of mucus contribute to impaired mucociliary transport during exacerbations of asthma, as well as with chronic bronchitis. Thomas et al evaluated the epithelial ultrastructure and ciliary function of patients with varying degrees of asthma severity and healthy controls. Subjects with severe asthma had a significantly lower number of ciliated cells and higher dyskinesia and cilia immotility indices, compared to healthy controls or those with mild or moderate asthma. ${ }^{22}$ Ciliary disorientation and a reduction in mean cilia beat frequency were found in subjects with moderate and severe asthma. ${ }^{22}$ Mucus hypersecretion and airways inflammation limit air flow during exacerbations of asthma. Typically, as bronchodilator and anti-inflammatory agents reverse the air-flow limitations, secretion clearance functions are restored.

An increased number of abnormal cilia are found with chronic bronchitis as well. Ciliary dysfunction is exacerbated by continued cigarette use. Compared to nonsmokers and ex-smokers with chronic bronchitis, those who continued to smoke had the highest percentage of ciliary abnormalities, as well as the presence of ciliary paralysis, features comparable to that found in bronchiectasis. ${ }^{23}$ Unlike asthma, mucociliary transport does not fully recover in chronic bronchitis. Recurrent infections and inflammation further reduce the number of ciliated epithelium. Hypersecretion of mucus with similar rheological characteristics to the mucus of those with $\mathrm{CF}$ limit air flow and affect the ability to generate effective cough flows. ${ }^{24}$ The increased propensity for mucus retention, recurrent inflammation, and infection damage conducting airways and inhibit restoration of mucociliary function.

Ciliary dysfunction in patients with $\mathrm{CF}$ is attributed to an abnormality of the gene that encodes for CF transmembrane conductance regulator. ${ }^{25}$ Dysregulation of the salt and water content may reduce airway surface liquid, inhibit ciliary function, and create an environment that is conducive to bacterial colonization and infection. ${ }^{26}$ As a result, an exaggerated inflammatory response occurs. The peripheral airways containing mucus filled bacteria are also host to inflammatory cells, and cellular breakdown products such as neutrophil-derived deoxyribonucleic acid and filamentous actin. ${ }^{27}$ Airways secretions are more viscous and adhesive, and therefore difficult to clear. This vicious circle of chronic infection, inflammation, and mucus stasis limits air flow in the larger airways and leads to the complete obstruction of the small peripheral airways 
and the development of diffuse, irreversible bronchiectasis. ${ }^{28,29}$

\section{Neurorespiratory Dysfunction and Secretion Clearance Problems}

Cough is a defense mechanism, initiated either voluntarily or by the stimulation of cough receptors located primarily in the central airways, which aids in the evacuation of secretions, and foreign substances from the respiratory tract..$^{30}$ Spinal cord pathology and/or diseases of the neurorespiratory system can impact the control of motor nerves, and, depending on the level of insult, interrupt or weaken respiratory muscle function. Cervical spinal cord injuries, especially those occurring between $\mathrm{C} 3$ and $\mathrm{C} 5$, affect diaphragmatic function, and contribute to respiratory insufficiency. Patients with high cervical injuries often require long-term mechanical ventilatory support. Injuries to the thoracic and lumbar spine interrupt abdominal and intercostal muscle function and impair cough function. ${ }^{31}$ Lack of an adequate cough contributes to the development of recurrent respiratory-tract infections and atelectasis and remains a major cause of death in this patient population. ${ }^{32}$

Chronic muscle disease, such as muscular dystrophies, and motor neuron diseases cause muscle fatigue and wasting. Respiratory muscle weakness can impair a cough mechanism by reducing expiratory flow, and the expulsion phase of a cough, which hinders secretion removal and the ability to maintain adequate lung function. ${ }^{33,34}$ Flow-volume loops may be performed and evaluated for the presence of cough spikes to determine cough effectiveness. Cough spikes are large increases in expiratory flow generated from the presence of enough intrathoracic pressure to cause dynamic compression of air within the large airways as the glottis is opened during a cough maneuver. ${ }^{35}$ In a study of 53 patients with motor neuron disease, Chaudri et al reported that subjects unable to generate cough spikes were at increased risk for pulmonary infection and death (79\% mortality rate), compared to those with the ability to generate cough spikes (50\% mortality rate). ${ }^{36}$

\section{Indications for Airway Clearance}

ACT is indicated for individuals whose function of the mucociliary escalator and/or cough mechanics are altered and whose ability to mobilize and expectorate airways secretions is compromised. Early diagnosis and implementation of ACT, coupled with medical management of infections and airways inflammation, can reduce morbidity and mortality associated with chronic pulmonary ${ }^{37,38}$ and neurorespiratory disease. ${ }^{39}$ Today a variety of interventions may be used to enhance airway clearance, with the goal of improving lung mechanics and gas exchange and preventing atelectasis and infection. Choosing the most appropriate airway-clearance device or technique for an individual patient requires integral knowledge of device function and limitations, as well as an assessment of the patient's cognitive ability and the severity of pulmonary impairment (Table 2).

\section{Where to Look for Current Evidence}

There is a lack of empirical evidence to support the superiority of any particular airway-clearance device or technique. There is much interest in developing evidencebased airway clearance protocols to guide device/technique selection. Searching through the literature to find the evidence may be a time-consuming venture. Therefore, it is important to become familiar with resources that are available to synthesize information, and the barriers that exist with respect to airway clearance research.

\section{Studies}

Evidence available in the literature can be categorized into pre-appraised levels ${ }^{40}$ (Fig. 2). Device evaluation and clinical studies lie at the base of this hierarchical structure. It is time and effort intensive to sift through the plethora of studies evaluating airway clearance techniques and devices. Moreover, there is a dearth of high level airway clearance research. High-level studies are prospective, randomized, blinded, placebo-controlled, and assess patientimportant outcomes. As a result, several methodological challenges to ACT research exist. Many clinical studies have very small sample sizes and are not adequately powered. It is often difficult for a single center, especially with disease conditions that are rare, to obtain a sufficient number of subjects, and therefore report results with small samples of subjects. ${ }^{41}$ Other challenges to designing and conducting valid clinical trials exist. Due to the size and design of ACT modalities, it is difficult to mask the treatment assignment to the subject and/or the research team, making blinding nearly impossible. Knowledge of the type and/or sequence of ACT provided may influence the subject's decision to enroll in or to continue with study participation. There is also the risk that the subject's personal preferences or the researcher's knowledge of the device being used may bias study outcomes. It is also difficult to control for variations in practice and use of ACTs.

Alterations in device use and adherence to protocol can unintentionally influence outcomes. For example, if percussion, postural drainage, and vibration were to be provided for a $30 \mathrm{~min}$ period to 10 consecutive patients by the same clinician, how could the researchers guarantee that the clapping and vibration were provided with the same intensity for each of those subjects? The length of the treatment of intervention may also have an impact. Since 
Airway Clearance Therapy: Finding the Evidence

Table 2. Age and Device Attributes to Consider When Matching Airway Clearance Techniques or Devices to Patient Need

\begin{tabular}{|c|c|c|c|}
\hline Technique & Age Considerations & Concurrent Aerosol Therapy & Other Factors to Consider \\
\hline $\begin{array}{l}\text { Postural drainage, clapping, and } \\
\text { vibration }\end{array}$ & No age limitations & Position specific & $\begin{array}{l}\text { Time/labor intensive } \\
\text { Need to modify postural drainage } \\
\text { positions } \\
\text { Requires a second caregiver }\end{array}$ \\
\hline Active cycle of breathing & $\begin{array}{l}\text { Introduce concepts at } 3-4 \text { years } \\
\text { of age } \\
\text { Coaching is required until } \\
\sim 10 \text { years of age }\end{array}$ & Yes & $\begin{array}{l}\text { Takes time to learn } \\
\text { Depending on the decline in } \mathrm{FEV}_{1} \text {, } \\
\text { may be difficult to perform } \\
\text { during exacerbations } \\
\text { Requires concentration }\end{array}$ \\
\hline Autogenic drainage & Begin at $\sim 10-12$ years of age & No & $\begin{array}{l}\text { Depending on the decline in } \mathrm{FEV}_{1} \text {, } \\
\text { may be difficult to perform } \\
\text { during exacerbations } \\
\text { Requires concentration } \\
\text { Takes time to learn }\end{array}$ \\
\hline $\begin{array}{l}\text { Oscillatory positive expiratory } \\
\text { pressure }\end{array}$ & Children, adults & Device specific & $\begin{array}{l}\text { Monitor pressures during therapy } \\
\text { to determine positive expiratory } \\
\text { pressure applied to airways }\end{array}$ \\
\hline $\begin{array}{l}\text { High frequency chest wall } \\
\text { compression }\end{array}$ & $>2-3$ years of age & Yes & $\begin{array}{l}\text { May be uncomfortable or difficult } \\
\text { to use with indwelling catheters } \\
\text { and chest tubes }\end{array}$ \\
\hline Exercise & Children, adults & No & $\begin{array}{l}\text { Risk of bronchospasm } \\
\text { Risk of oxygen desaturation }\end{array}$ \\
\hline
\end{tabular}

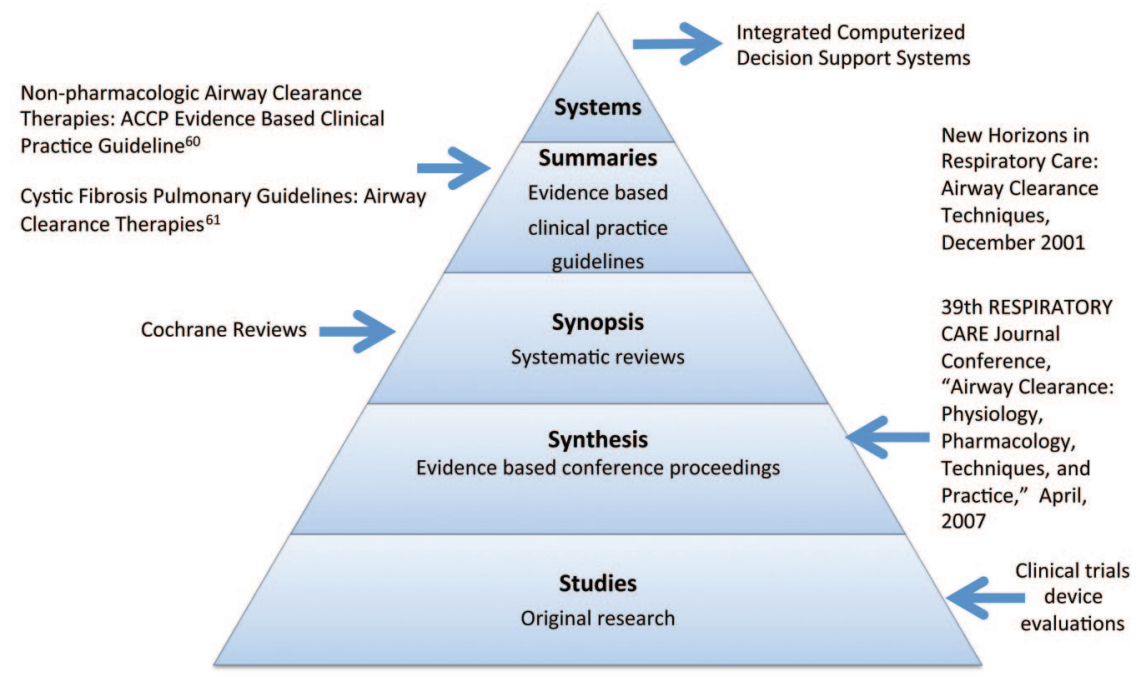

Fig. 2. A hierarchical structure for classifying pre-appraised evidence, which can be used to evaluate the resources available to clinicians interested in appraising airway clearance research. (From reference 40, with permission.)

ACT is time-consuming, poor adherence to the study protocol, and/or lack of device use may occur. ${ }^{42}$ Several studies have suggested that poor adherence to prescribed ACT exists across all age ranges. For example, school-age children demonstrated ACT adherence rates of $51-74 \%,{ }^{42}$ approximately 50\% during adolescence, ${ }^{43}$ and $30-32 \%$ among adults. ${ }^{44}$ Lack of adherence has been linked to lengthy treatment times, ${ }^{45}$ perceived lack of efficacy for the prescribed intervention, ${ }^{46}$ coping mechanisms, ${ }^{47}$ level of education, ${ }^{48}$ and personal preference ${ }^{49}$ for the ACT device or modality. To accurately evaluate the effectiveness of ACTs it is essential to monitor and determine adherence to therapy.

There is also sparse use of sham treatment. ${ }^{50}$ Sham treatment is a medical procedure, analogous to a placebo, which is given to a control group of subjects, to enable the 
Table 3. A Summary of Clinical Practice Guideline Recommendations

\begin{tabular}{lc}
\hline \hline Cystic Fibrosis Pulmonary Guidelines: Airway Clearance Therapies ${ }^{60}$ & $\begin{array}{c}\text { Nonpharmacologic Airway Clearance Therapies: American College } \\
\text { of Chest Physicians Evidence-Based Clinical Practice Guidelines }\end{array}$ \\
\hline $\begin{array}{l}\text { Airway-clearance therapy is recommended for all patients with cystic } \\
\text { fibrosis, for clearance of sputum, maintenance of lung function, } \\
\text { and improved quality of life. }\end{array}$ & $\begin{array}{c}\text { Postural drainage, clapping, and vibration has relatively modest } \\
\text { effectiveness, with unproven long-term benefits. }\end{array}$ \\
$\begin{array}{l}\text { No airway-clearance therapy has been demonstrated to be superior to } \\
\text { any other. }\end{array}$ & $\begin{array}{c}\text { Manually assisted cough and cough assist should be considered for } \\
\text { patients with expiratory muscle weakness and impaired cough, } \\
\text { to reduce the incidence of respiratory complications. }\end{array}$ \\
$\begin{array}{l}\text { For the individual, one form of airway-clearance therapy may be } \\
\text { superior to the others. The prescription of airway-clearance } \\
\text { therapy should be individualized, based on factors such as age, } \\
\text { patient preference, and adverse events, among others. } \\
\text { Aerobic exercise is recommended for patients with cystic fibrosis, as } \\
\text { an adjunctive therapy for airway clearance and its additional with air-flow obstruction, such as COPD. } \\
\text { benefits to overall health. }\end{array} \begin{array}{c}\text { Huffing and autogenic drainage should be taught as an adjunct to } \\
\text { other methods of sputum clearance in patients with COPD and } \\
\text { cystic fibrosis. } \\
\text { Oscillatory positive expiratory pressure, high frequency chest wall } \\
\text { compression, and positive expiratory pressure are effective } \\
\text { alternatives to postural drainage, clapping and vibration. } \\
\text { Expiratory muscle training is recommended for patients with } \\
\text { neuromuscular weakness and impaired cough to improve peak } \\
\text { expiratory pressure. } \\
\text { Long term outcomes of airway clearance therapy are unknown. }\end{array}$
\end{tabular}

effects of the supposedly "active" treatment to be assessed objectively. A sham treatment is not necessarily expected to be ineffective. Rather, the purpose of a sham treatment group is to identify any specific benefit of one element of a medical treatment above and beyond all benefits that might be attributed to everything else about that treatment. Since ineffective mucociliary clearance leads to increased morbidity and mortality, ethical considerations deter the use of sham treatment in ACT research.

\section{Synthesis}

Conference proceedings review the clinical evidence and scientific basis for diagnosis and treatment of diseases or the use of therapeutic modalities. For respiratory therapists the New Horizons Symposiums and Respiratory Care Journal Conferences provide a venue for clinical experts and scientists to review and present evidence specific to our practice. Conference proceedings are then published in RESPIRATORY CARE. Two conference proceedings were dedicated to airway clearance: the New Horizons Symposium, presented at the 47th AARC Congress in December, 2001, and the 39th RESPIRATORY CARE Journal Conference, conducted in April, 2007. The scientific evidence with respect to the physiology of mucus production and cough, pharmacologic management, and non-pharmacologic approaches to airway clearance were presented and discussed, and findings summarized. The aforementioned narrative reviews also provide recommendations for new directions and opportunities for future research and clinical care.

\section{Systematic Reviews}

A systematic review is a summary of the literature that uses an organized method to thoroughly search, critically appraise, and statistically combine data from valid studies in the literature. ${ }^{51}$ This evaluation is performed systematically and rigorously, the results of which are based on the strength of the evidence found in the literature. Systematic ACT reviews are available and include reviews of specific techniques, such as active cycle of breathing, ${ }^{52}$ positive expiratory pressure devices, ${ }^{53}$ and oscillatory positive expiratory pressure devices, ${ }^{54}$ as well as sequencing pharmacologic agents, 55,56 and comparing therapeutic modalities for specific diseases such as $\mathrm{CF}^{57}$ or COPD. ${ }^{58}$

\section{Evidenced-Based Clinical Practice Guidelines}

In the last decade, 2 airway clearance clinical practice guidelines have been published. Guided by systematic review of the literature from multiple databases and hand searches, authors constructed recommendations for the non-pharmacologic management of secretion clearance in pulmonary disease ${ }^{59}$ and the use of airway clearance for the treatment of CF lung disease. ${ }^{60}$ The authors acknowledged methodological limitations of airway clearance research, and reported recommendations made through these guidelines were derived from a "fair" level of evidence, or data that were valid enough to make plausible conclusions in the absence of rigorously conducted scientific studies. Recommendations were provided with re- 


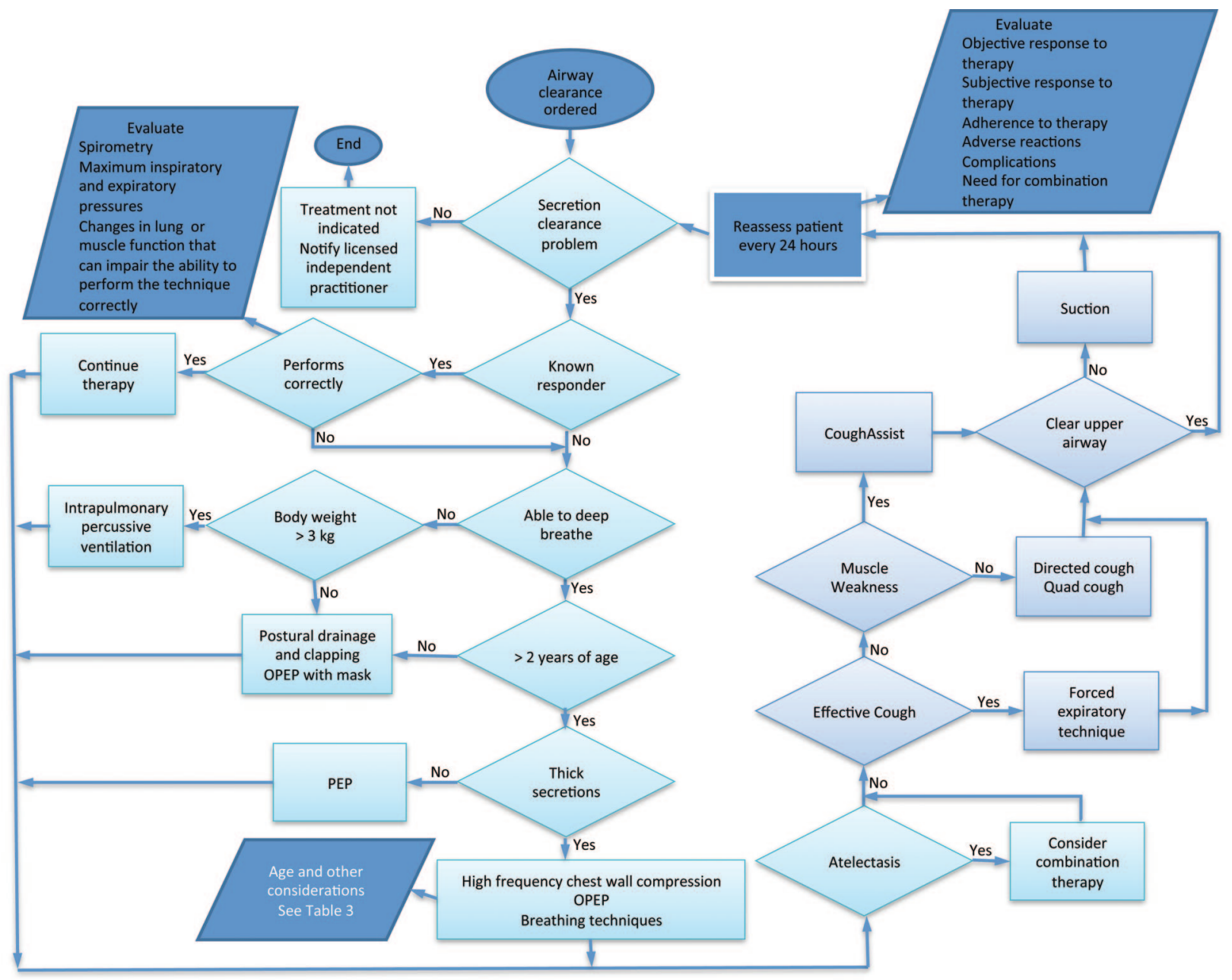

Fig. 3. Respiratory therapist driven algorithm to guide airway clearance use. OPEP = oscillatory positive expiratory pressure.

spect to the general needs for airway clearance, as well as for treatment of individual patients. A summary of the pertinent findings from these guidelines can be found in Table 3 .

\section{Putting Evidence Into Practice}

The lack of empirical evidence to determine superiority of any airway-clearance device or technique supports the need for protocols to guide device/technique selection. The literature supports the use of respiratory therapist-driven protocols. Studies demonstrate that protocol use improves appropriate allocation of respiratory services, by reducing over-ordering and under-ordering of respiratory therapies, and the cost of care. ${ }^{61-64} \mathrm{~A}$ few studies report that matching ACT to clinical need improves patient adherence and reduces missed therapy, especially when the patients are educated consumers of care and actively engaged in the ACT selection process. ${ }^{65-68}$
An algorithm for guiding ACT was proposed ${ }^{17}$ but did not account for an assessment of the patient's ability to perform therapy, determination of cough characteristics, or frequency of re-evaluation. This algorithm recommends to "continue effective therapy" if the patient is a "known responder."17 However, decline in pulmonary and/or muscle function can occur during exacerbations or with time, as a function of the natural progression of the disease. The rate of decline in muscle and/or pulmonary function can affect treatment efficacy and patient outcomes. Evaluation of the need for ACT and use of a particular device or technique must include initial and ongoing assessment of the patient's lung function, muscle strength, and cognitive ability to perform the therapy. Figure 3 integrates expert opinion, ${ }^{12,17}$ evidence from published systematic reviews, ${ }^{52-54,57,58}$ and clinical practice guidelines ${ }^{59,60}$ to construct an algorithm to guide the use of ACT. The establishment and evaluation of patient, process, and financial outcomes are crucial elements in 
Decision support

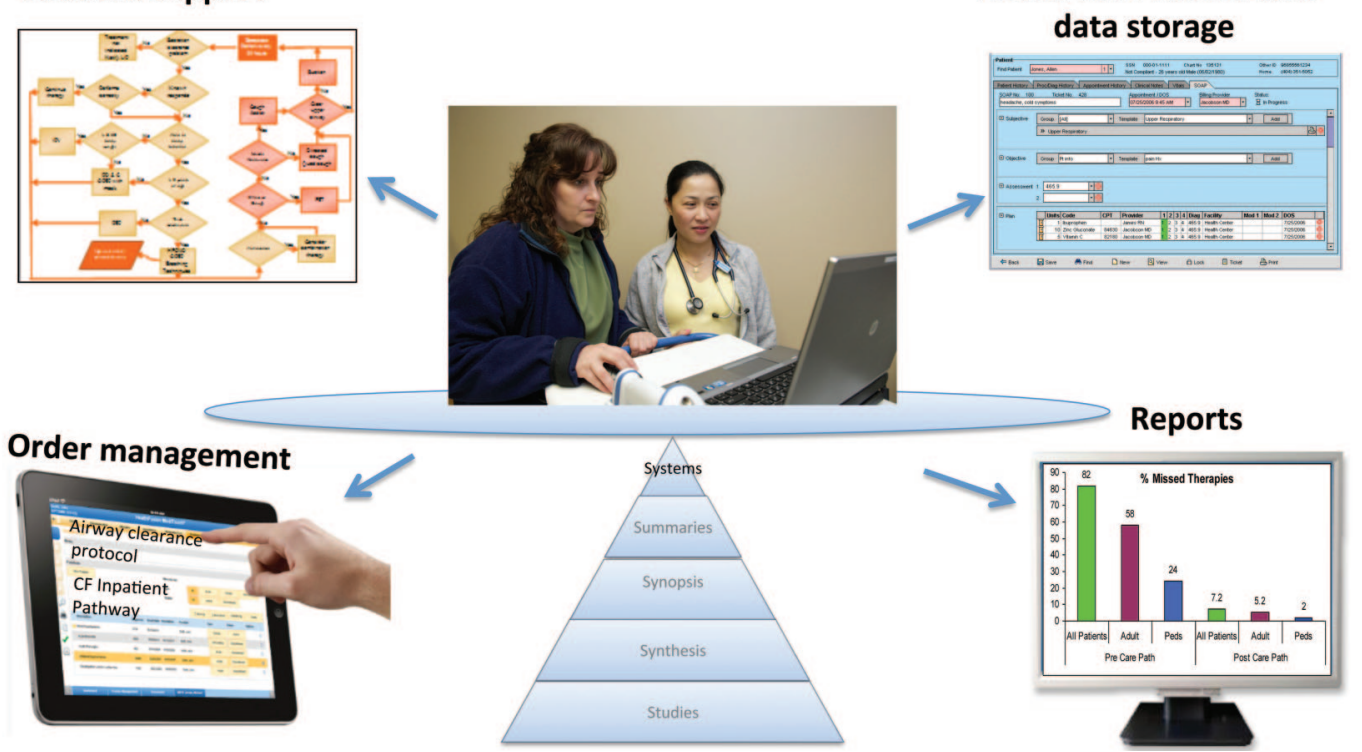

Fig. 4. An example of an integrated system for storing health information, guiding and evaluating clinical care.

protocol implementation. A computerized system provides an efficient and cost-effective method for evaluating outcomes. ${ }^{69}$

An electronic medical record provides the potential to create an integrated system to guide practice, store health information, and evaluate patient and process outcomes (Fig. 4). It is important not only to house protocols and clinical pathways, but also to have an electronic health record that can easily perform protocol or pathway audits to determine allocation of services and patient and process outcomes. Collecting outcome variables, such as hospital or ICU stay, re-visitation rates, delays in care, missed therapy, and order variances, can waste human capital if the data collection process is cumbersome and timeconsuming.

\section{Summary}

ACT has for decades been considered one of the cornerstones of therapy for the prevention and treatment of pulmonary disease and neurorespiratory dysfunction. Although there are methodological challenges that make it difficult to evaluate the clinical efficacy of ACTs clinically, literature does exist to guide our practice. An integral knowledge of ACTs (limitations of use derived from the literature, recommendations from narrative and systematic reviews, and evidence-based clinical practice guidelines), device performance, and patient characteristics (disease state, lung and muscle function, cognitive ability, preferences) is needed to construct evidence-based approaches to guide care.

\section{REFERENCES}

1. Rubin BK. Physiology of airway mucus clearance. Respir Care 2002; 47(7):761-768

2. Warwick WJ. Mechanisms of mucous transport. Eur J Respir Dis Suppl 1983;127:162-167.

3. Foster WM. Mucociliary transport and cough in humans. Pulm Pharmacol Ther 2002;15(3):277-282.

4. Zaugg M, Lucchinetti E. Respiratory function in the elderly. Anesthesiol Clin North America 2000;18(1):47-58.

5. Hernandez ML, Harris B, Lay JC, Bromberg PA, Diaz-Sanchez D, Devlin $\mathrm{RB}$, et al. Comparative airway inflammatory response of normal volunteers to ozone and lipopolysaccharide challenge. Inhal Toxicol 2010;22(8):648-656.

6. Habesoglu M, Demir K, Yumusakhuylu AC, Yilmaz AS, Oysu C. Does passive smoking have an effect on nasal mucociliary clearance? Otolaryngol Head Neck Surg 2012;147(1):152-156.

7. Chaudri MB, Liu C, Hubbard R, Jefferson D, Kinnear WJ. Relationship between supermaximal flow during cough and mortality in motor neurone disease. Eur Respir J 2002;19(3):434-438.

8. Hadjikoutis S, Wiles CM. Respiratory complications related to bulbar dysfunction in motor neuron disease. Acta Neurol Scand 2001; 103(4):207-213.

9. Van der Schans CP. Bronchial mucus transport. Respir Care 2007; 52(9):1150-1158.

10. Voynow JA, Rubin BK. Mucins, mucus, and sputum. Chest 2009; 135(2):505-512.

11. Rubin BK. Mucus, phlegm, and sputum in cystic fibrosis. Respir Care 2009;54(6):726-32.

12. Lester MK, Flume PA. Airway-clearance therapy guidelines and implementation. Respir Care 2009;54(6):733-750.

13. Lapin CD. Airway physiology, autogenic drainage, and active cycle of breathing. Respir Care 2002;47(7):778-85.

14. Pryor JA. Physiotherapy for airway clearance in adults. Eur Respir J 1999;14(6):1418-1424. 


\section{Airway Clearance Therapy: Finding the Evidence}

15. Walsh BK, Hood K, Merritt G. Pediatric airway maintenance and clearance in the acute care setting: how to stay out of trouble. Respir Care 2011;56(9):1424-1440.

16. Myers TR. Positive expiratory pressure and oscillatory positive expiratory pressure therapies. Respir Care 2007;52(10):1308-1326.

17. Chatburn RL. High-frequency assisted airway clearance. Respir Care 2007;52(9):1224-1235.

18. Gauld LM. Airway clearance in neuromuscular weakness. Dev Med Child Neurol 2009;51(5):350-355.

19. Armengot M, Milara J, Mata M, Carda C, Cortijo J. Cilia motility and structure in primary and secondary ciliary dyskinesia. Am J Rhinol Allergy 2010;24(3):175-180.

20. Carlén B, Stenram U. Primary ciliary dyskinesia: a review. Ultrastruct Pathol 2005;29(3-4):217-220.

21. Santamaria F, Montella S, Tiddens HA, Guidi G, Casotti V, Maglione M, de Jong PA. Structural and functional lung disease in primary ciliary dyskinesia. Chest 2008;134(2):351-357.

22. Thomas B, Rutman A, Hirst RA, Haldar P, Wardlaw AJ, Bankart J, et al. Ciliary dysfunction and ultrastructural abnormalities are features of severe asthma. J Allergy Clin Immunol 2010;126(4):722-729.

23. Verra F, Escudier E, Lebargy F, Bernaudin JF, De Crémoux H, Bignon J. Ciliary abnormalities in bronchial epithelium of smokers, ex-smokers, and nonsmokers. Am J Respir Crit Care Med 1995; 151(3 Pt 1):630-634.

24. Jeffery PK. Comparative morphology of the airways in asthma and chronic obstructive pulmonary disease. Am J Respir Crit Care Med 1994;150(5 Pt 2):S6-S13.

25. Boucher RC. Evidence for airway surface dehydration as the initiating event in CF airway disease. J Intern Med 2007;261(1):5-16.

26. Boucher RC. Cystic fibrosis: a disease of vulnerability to airway surface dehydration. Trends Mol Med 2007;13(6):231-240.

27. Rubin BK. Mucus structure and properties in cystic fibrosis. Paediatr Respir Rev 2007;8(1):4-7.

28. Belessis Y, Dixon B, Hawkins G, Pereira J, Peat J, MacDonald R, et al. Early cystic fibrosis lung disease detected by bronchoalveolar lavage and lung clearance index. Am J Respir Crit Care Med 2012; 185(8):862-873

29. Regamey N, Tsartsali L, Hilliard TN, Fuchs O, Tan HL, Zhu J, Qiu YS, Alton EW, Jeffery PK, Bush A, Davies JC. Distinct patterns of inflammation in the airway lumen and bronchial mucosa of children with cystic fibrosis. Thorax 2012;67(2):164-170.

30. Rubin BK. The role of mucus in cough research. Lung 2010;188(Suppl 1):S69-S72

31. Zimmer MB, Nantwi K, Goshgarian HG. Effect of spinal cord injury on the respiratory system: basic research and current clinical treatment options. J Spinal Cord Med 2007;30(4):319-330.

32. Brown R, DiMarco AF, Hoit JD, Garshick E. Respiratory dysfunction and management in spinal cord injury. Respir Care 2006;51(8): 853-868.

33. Fairclough RJ, Bareja A, Davies KE. Progress in therapy for Duchenne muscular dystrophy. Exp Physiol 2011;96(11):1101-1113.

34. Chandrasoma B, Balfe D, Naik T, Elsayegh A, Lewis M, Mosenifar Z. Pulmonary function in patients with amyotrophic lateral sclerosis at disease onset. Monaldi Arch Chest Dis 2012;77(3-4): 129-133.

35. Beardsmore CS, Wimpress SP, Thomson AH, Patel HR, Goodenough P, Simpson H. Maximum voluntary cough: an indication of airway function. Bull Eur Physiopathol Respir 1987;23(5):465-472.

36. Chaudri MB, Liu C, Hubbard R, Jefferson D, Kinnear WJ. Relationship between supramaximal flow during cough and mortality in motor neurone disease. Eur Respir J 2002;19(3):434-438.

37. Davis PB. Cystic fibrosis since 1938. Am J Respir Crit Care Med 2006;173(5):475-482.
38. Sivasothy P, Brown L, Smith IE, Shneerson JM. Effect of manually assisted cough and mechanical insufflation on cough flow of normal subjects, patients with chronic obstructive pulmonary disease (COPD), and patients with respiratory muscle weakness. Thorax 2001;56(6):438-444.

39. Perrin C, Unterborn JN, Ambrosio CD, Hill NS. Pulmonary complications of chronic neuromuscular diseases and their management. Muscle Nerve 2004;29(1):5-27.

40. Hayes RB. Of studies, syntheses, synopses and systems: the " $4 \mathrm{~S}$ " evolution of services for finding the current best evidence. ACP J Club 2001;134(2):A11-A13.

41. Pattishall EN. Negative clinical trials in cystic fibrosis research. Pediatrics 1990;85(3):277-281.

42. Modi AC, Cassedy AE, Quittner AL, Accurso F, Sontag M, Koenig JM, Ittenbach RF. Trajectories of adherence to airway clearance therapy for patients with cystic fibrosis. J Pediatr Psychol 2010; 35(9):1028-1037.

43. Modi AC, Lim CS, Yu N, Geller D, Wagner MH, Quittner AL. A multi-method assessment of treatment adherence for children with cystic fibrosis. J Cyst Fibros 2006;5(3):177-185.

44. Arias Llorente RP, Bousoño García C, Díaz Martín JJ. Treatment compliance in children and adults with cystic fibrosis. J Cyst Fibros 2008;7(5):359-367.

45. Bernard RS, Cohen LL. Increasing adherence to cystic fibrosis treatment: a systematic review of behavioral techniques. Pediatr Pulmonol 2004;37(1):8-16.

46. Kettler LJ, Sawyer SM, Winefield HR, Grenville HW. Determinants of adherence in adults with cystic fibrosis. Thorax 2002;57(5): 459-464.

47. Grossoehme DH, Opipari-Arrigan L, VanDyke R, Thurmond S, Seid M. Relationship of adherence determinants and parental spirituality in cystic fibrosis. Pediatr Pulmonol 2012;47(6):558-566.

48. Flores JS, Teixeira FÂ, Rovedder PM, Ziegler B, Dalcin Pde T. Adherence to airway clearance therapies by adult cystic fibrosis patients. Respir Care 2013;58(2):279-285.

49. Myers LB, Horn SA. Adherence to chest physiotherapy in adults with cystic fibrosis. J Health Psychol 2006;11(6):915-926.

50. Hess DR. The evidence for secretion clearance techniques. Respir Care 2001;46(11):1276-1293.

51. Cook DJ. Moving toward evidence-based practice. Respir Care 2003; 48(9):859-868.

52. McKoy NA, Saldanha IJ, Odelola OA, Robinson KA. Active cycle of breathing technique for cystic fibrosis. Cochrane Database Syst Rev 2012;(12):CD007862.

53. Elkins MR, Jones A, van der Schans C. Positive expiratory pressure physiotherapy for airway clearance in people with cystic fibrosis. Cochrane Database Syst Rev 2006;(2):CD003147.

54. Morrison L, Agnew J. Oscillating devices for airway clearance in people with cystic fibrosis. Cochrane Database Syst Rev 2009;(1): CD006842.

55. Elkins M, Dentice R. Timing of hypertonic saline inhalation for cystic fibrosis. Cochrane Database Syst Rev 2012;(2):CD008816.

56. Dentice R, Elkins M. Timing of dornase alfa inhalation for cystic fibrosis. Cochrane Database Syst Rev 2011;(5):CD007923.

57. Main E, Prasad A, Schans C. Conventional chest physiotherapy compared to other airway clearance techniques for cystic fibrosis. Cochrane Database Syst Rev 2005;(1):CD002011.

58. Osadnik CR, McDonald CF, Jones AP, Holland AE. Airway clearance techniques for chronic obstructive pulmonary disease. Cochrane Database Syst Rev 2012;(3):CD008328.

59. Cool FD, Rosen MJ. Nonpharmacologic airway clearance therapies: ACCP evidence-based clinical practice guidelines. Chest 2006;129 (1 Suppl):250S-259S. 


\section{Airway Clearance Therapy: Finding the Evidence}

60. Flume PA, Robinson KA, O'Sullivan BP, Finder JD, Vender RL, Willey-Courand DB, et al; Clinical Practice Guidelines for Pulmonary Therapies Committee. Cystic fibrosis pulmonary guidelines: airway clearance therapies. Respir Care 2009;54(4):522-537.

61. Kallam A, Meyerink K, Modrykamien AM. Physician-ordered aerosol therapy versus respiratory therapist-driven aerosol protocol: the effect on resource utilization. Respir Care 2013;58(3):431-437.

62. Colice GL, Carnathan B, Sung J, Paramore LC. A respiratory therapist-directed protocol for managing inpatients with asthma and COPD incorporating a long-acting bronchodilator. J Asthma 2005;42(1):29-34.

63. Drescher GS, Carnathan BJ, Imus S, Colice GL. Incorporating tiotropium into a respiratory therapist-directed bronchodilator protocol for managing in-patients with COPD exacerbations decreases bronchodilator costs. Respir Care 2008;53(12):1678-1684.

64. Kollef MH, Shapiro SD, Clinkscale D, Cracchiolo L, Clayton D,
Wilner R, Hossin L. The effect of respiratory therapist-initiated treatment protocols on patient outcomes and resource utilization. Chest 2000;117(2):467-475.

65. Shapiro BA, Cane RD, Peterson J, Weber D. Authoritative medical direction can assure cost-beneficial bronchial hygiene therapy. Chest 1988;93(5):1038-1042.

66. Alexander E, Weingarten S, Mohsenifar Z. Clinical strategies to reduce utilization of chest physiotherapy without compromising patient care. Chest 1996;110(3):430-432.

67. Homnock DN. Making airway clearance successful. Paediatr Respir Rev 2007;8(1):40-45.

68. White D, Stiller K, Haensel N. Adherence of adult cystic fibrosis patients with airway clearance and exercise regimens. J Cyst Fibros 2007;6(3):163-170.

69. Christman SL, Volsko TA. Evaluation of an oxygen protocol in long-term care. Respir Care 2006;51(12):1424-1431. 